removed $^{1}$; however, the contaminated needle puncture may be associated with subsequent mediastinal infection, so empirical antimicrobial therapy is suggested in selected cases. ${ }^{6}$

In conclusion, surgeons could consider EBUS-TBNA as an effective and alternative option in the diagnosis, subsequent surgical intervention, and identification of the causative agent of mediastinal infections in patients who are unable to undergo surgery.

\section{References}

1. Medford AR, Bennett JA, Free CM, Agrawal S. Endobronchial ultrasound-guided transbronchial needle aspiration (EBUS-TBNA): applications in chest disease. Respirology. 2010;15:71-9.
2. Yokote K, Osada H, Tsukada H, Kurisu S, Taira Y, Yamate N. Treatment of mediastinal abscess. Nippon Kokyu Geka Gakkai Zasshi. 1998;12:74-9.

3. Tanaka T, Inaba Y, Arai Y, Matsueda K, Aramaki T, Dendo S. Mediastinal abscess successfully treated by percutaneous drainage using a unified CT and fluoroscopy system. Br J Radiol. 2002;75:470-3.

4. Nakajima T, Yasufuku K, Shibuya K, Fujisawa T. Endobronchial ultrasoundguided transbronchial needle aspiration for the treatment of central airway stenosis caused by a mediastinal cyst. Eur J Cardiothorac Surg. 2007;32: 538-40.

5. Meseguer SM, Franco SJ. [Drainage of a mediastinal cyst by endobronchial ultrasound-guided needle aspiration]. Arch Bronconeumol. 2010;46:206-12. Spanish.

6. Huang CT, Chen CY, Ho CC, Yu CJ. A rare constellation of empyema, lung abscess, and mediastinal abscess as a complication of endobronchial ultrasound-guided transbronchial needle aspiration. Eur J Cardiothorac Surg. 2011;40:264-5.

\title{
Dissected axillary artery cannulation in redo-total arch replacement surgery
}

\author{
Prashanth Vallabhajosyula, MD, R. Scott McClure, MD, C. William Hanson III, MD, and \\ Y. Joseph Woo, MD, Philadelphia, Pa
}

Despite the increased use of axillary artery cannulation in aortic surgery, extension of an aortic dissection into the axillary artery remains a relative contraindication to its use. Deleterious effects associated with false lumen cannulation are of real concern and particular consequence with the axillary artery. Blood flow into the false lumen at this level risks cerebral malperfusion because of the proximity of the cerebral vessels. We describe a case of successful transesophageal echocardiography-guided true lumen cannulation of a dissected axillary artery in the face of accompanying distal dissection into the femoral vessels during complex redo aortic arch surgery.

Axillary artery cannulation has become the preferred strategy for many surgeons when reconstructing the ascending aorta or the aortic arch. ${ }^{1}$ Key benefits to axillary artery cannulation include the ability to maintain antegrade systemic blood flow during cardiopulmonary bypass, as well as enabling selective antegrade cerebral

\footnotetext{
From the Division of Cardiovascular Surgery, Department of Surgery, University of Pennsylvania School of Medicine, Hospital of the University of Pennsylvania, Philadelphia, Pa.

Disclosures: Authors have nothing to disclose with regard to commercial support.

Received for publication Nov 10, 2012; accepted for publication Feb 12, 2013; available ahead of print March 13, 2013.

Address for reprints: Y. Joseph Woo, MD, Division of Cardiovascular Surgery,

Department of Surgery, 3400 Spruce St, 6 Silverstein, Philadelphia, PA 19104

(E-mail: wooy@uphs.upenn.edu).

J Thorac Cardiovasc Surg 2013;145:e57-9

0022-5223/\$36.00

Copyright (c) 2013 by The American Association for Thoracic Surgery

http://dx.doi.org/10.1016/j.jtcvs.2013.02.020
}

perfusion via positioning of a clamp onto the proximal innominate artery. ${ }^{1}$ Although contraindications to this technique are few, an aortic dissection that extends into the axillary artery is a perceived relative contraindication to its use. ${ }^{2}$ Typically, the lumen of an arterial dissection is predominantly that of the false lumen, with the true lumen relegated to less than $50 \%$ of the original diameter. With the smaller diameter of the axillary artery, access to the true lumen in the face of a dissection can be rather challenging. Undetected cannulation of the false lumen with the establishment of cardiopulmonary bypass has the potential to be catastrophic, causing severe cerebral malperfusion. Still, in situations in which alternative arterial access is prohibitive, true lumen cannulation of a dissected vessel can be an invaluable technique. We report a case of successful transesophageal echocardiography-guided true lumen cannulation of a dissected axillary artery in a patient with chronic aneurysmal dissection of the aortic arch and descending thoracic aorta several years after a previous ascending aortic repair for a DeBakey type I aortic dissection. ${ }^{3}$

\section{CLINICAL SUMMARY}

A 60-year-old African American man with a medical history of poorly controlled essential hypertension, 12 years after ascending aorta and hemiarch repair of a DeBakey type I aortic dissection in conjunction with an aortic valve resuspension, presented to the hospital with shortness of breath. Cardiac workup revealed new-onset atrial fibrillation, severe aortic insufficiency with aortic root dilatation, 


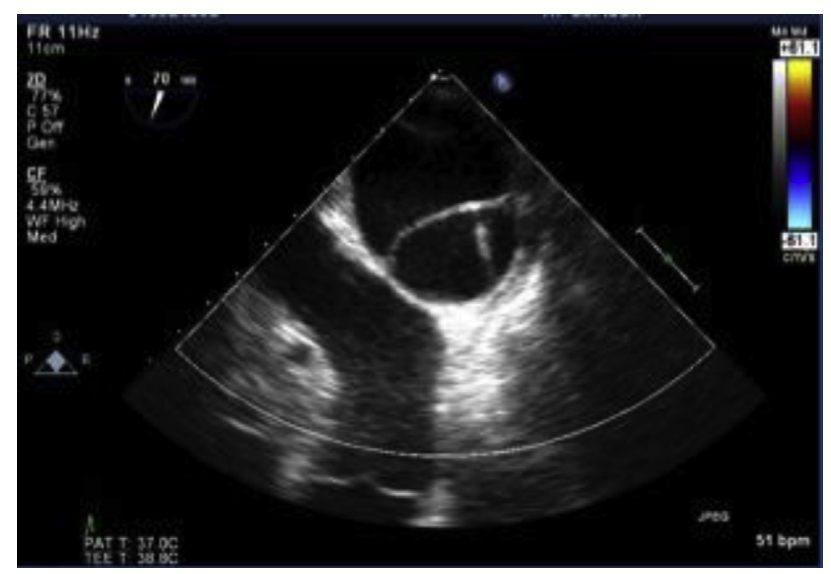

FIGURE 1. Transesophageal short-axis image of the dissected right axillary artery with both the false lumen (superior, larger lumen) and true lumen (inferior, smaller lumen) in view. Wire access of the true lumen is easily identifiable, enabling safe true lumen cannulation to occur.

and chronic aneurysmal dissection of the aortic arch and descending thoracic aorta. Left ventricular function was mildly diminished. No other valvular abnormalities were identified. Given the acute on chronic presentation, the patient was taken to the operating room for redo sternotomy, aortic root replacement, and elephant trunk total arch reconstruction (Figure 1).

Preoperative computed tomographic angiography confirmed a complex chronic residual aneurysmal dissection with an intimal flap originating in the aortic arch, the true lumen almost entirely encircled by the false lumen. The dissection coursed superiorly into the right axillary artery and both carotid arteries in conjunction with its inferior extension deep into the femoral vessels bilaterally. We knew that an extended period of circulatory arrest was imminent for surgical repair (warranting selective antegrade cerebral perfusion), with both the right axillary and femoral arteries chronically dissected, and successful true lumen cannulation of the right axillary artery was thought to be the most advantageous approach to the overall conduct and safety of the operation.

Bilateral radial arterial lines were placed. An infraclavicular incision was performed, and the right axillary artery was exposed. The false lumen of the axillary artery was entered with a 21-gauge Micropuncture Kit needle (Cook Medical Inc, Bloomington, Ind). The needle was guided through the intimal flap and into the true lumen. By using Seldinger's technique, a guidewire was placed through the needle and into the true lumen of the aortic arch under the guidance of transesophageal echocardiography (Figure 2).

Having achieved wire access, a redo sternotomy was performed, and the chest was safely reentered. The heart and great vessels were dissected free of adhesions, and full heparinization was administered.

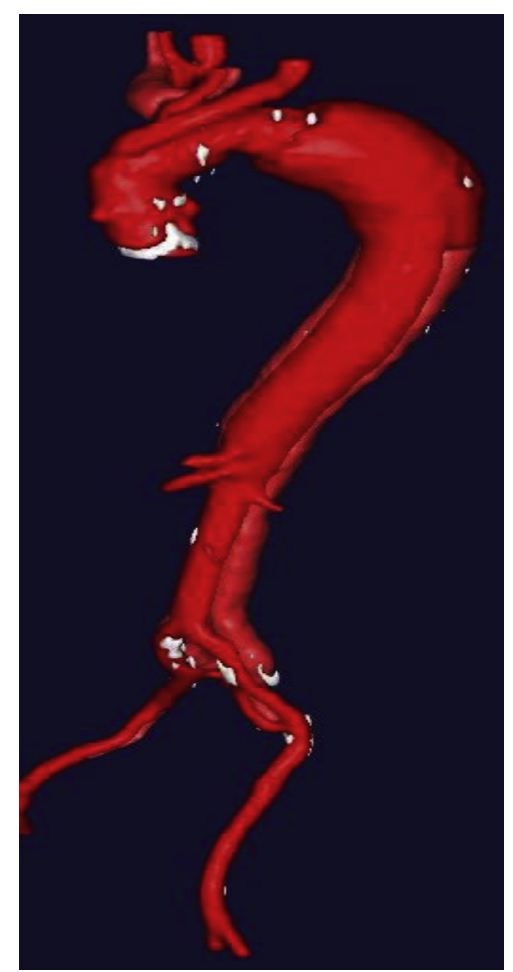

FIGURE 2. Postoperative computed tomography 3-dimensional image showing completed arch reconstruction with distal elephant trunk and residual chronic dissection of the descending thoracic and abdominal aorta.

The right axillary artery was then cannulated. A 5F sheath was advanced over the guidewire from the Micropuncture Kit. Again, using Seldinger's technique, the guidewire was removed and replaced with the heavier-gauge Bentson guidewire (Cook Medical Inc). The Bentson wire was situated in the true lumen of the descending thoracic aorta. After serial dilatations over the Bentson wire, an $18 \mathrm{~F}$ arterial cannula was advanced into the true lumen and flow was confirmed. Transesophageal echocardiography was used for visual guidance throughout the entire process.

The right atrium was cannulated, cardiopulmonary bypass was commenced, and the patient was cooled to $24^{\circ} \mathrm{C}$. The aorta was crossclamped, the heart was arrested, and the aortic root was replaced with a bioprosthetic composite valve graft. Once complete, the aortic arch was replaced under hypothermic circulatory arrest with adjunct selective antegrade cerebral perfusion via the axillary artery with clamping of the innominate artery. Cerebral status was monitored with near-infrared spectroscopy in conjunction with electroencephalography. A Vascutek Siena multibranched graft (Terumo Cardiovascular Systems, Ann Arbor, Mich) was used for the total arch reconstruction. A $7-\mathrm{cm}$ elephant trunk was left in the proximal descending thoracic aorta. 
After completion of the distal anastomosis to the descending thoracic aorta and the anastomosis to the left carotid artery, cardiopulmonary bypass was reinstituted centrally through a side-arm extension of the multibranched graft. With cerebral and systemic flow restored, anastomoses to the innominate and left subclavian arteries were then completed. A graft-to-graft anastomosis completed the procedure, and the patient was weaned from cardiopulmonary bypass. The axillary artery was decannulated, followed by patch repair of the vessel using autologous pericardium. Equal line pressures were noted in the radial arterial lines bilaterally.

The patient had a prolonged but uncomplicated hospital course. At 6 months follow-up, the repair was intact and the patient continued to be doing well.

\section{DISCUSSION}

In an all-comer retrospective analysis of DeBakey I and II aortic dissections at the University of Pennsylvania, the risk of reoperation at 10 years for proximal and distal pathologies was $22.2 \%$ and $24.6 \%$, respectively. ${ }^{4}$ This patient presented with both proximal (aortic root dilatation with severe aortic insufficiency) and distal (aneurysmal expansion) pathologies 12 years after his initial operation. Because an extended circulatory arrest period is required for this type of reoperative reconstruction, we thought that true lumen cannulation of the dissected right axillary artery was the more optimal arterial cannulation strategy, as opposed to attempting to cannulate the dissected femoral vessels or the previously constructed hemiarch graft directly. Although either of these alternative options are acceptable contingency strategies and would have been used had axillary artery cannulation been unsuccessful, both alternatives require direct insertion of malleable cannulas into the cerebral vessels for antegrade cerebral perfusion. This approach is at times a cumbersome exercise that clutters the operative field and impedes the conduct of operation. In our opinion, when axillary artery cannulation can be performed safely, it substantially simplifies the management of the cerebral circulation.

Our practice for repairing DeBakey I and II aortic dissections has evolved with time from peripheral cannulation of nondissected vessels to direct true lumen central cannulation of the dissected ascending aorta with echocardiographic guidance. Our success with this approach influenced our decision to cannulate the true lumen of the dissected axillary artery in this particular situation. We have since extended this technique to true lumen cannulation of the dissected descending thoracic aorta for thoracoabdominal repair in patients with chronic aneurysmal DeBakey type I aortic dissections. Our preliminary results suggest that this can be used safely without increasing postoperative mortality or neurologic injury. ${ }^{5}$

\section{CONCLUSIONS}

Late reoperation after prior repair for an aortic dissection carries an operative mortality of $4 \%$ to $31 \%$ in contemporary literature. ${ }^{4,6}$ Moreover, survivors from redo aortic procedure have a 2-fold increase in late death compared with age-matched controls. ${ }^{4}$ This illustrates the chronic nature of acute aortic dissection and the necessity to follow these patients long-term. When such cases present, access for cannulation is often not a straightforward event because the chronic dissection has extended out to the peripheral vessels. True lumen cannulation of the dissected axillary artery is a particularly useful technique in such complex aortic arch cases.

\section{References}

1. Strauch JT, Spielvogel D, Lauten A, Lansman SL, McMurtry K, Bodian CA, et al. Axillary artery cannulation: routine use in ascending aorta and aortic arch replacement. Ann Thorac Surg. 2004;78:103-8.

2. Schachner T, Nagiller J, Zimmer A, Laufer G, Bonatti J. Technical problems and complications of axillary artery cannulation. Eur J Cardiothorac Surg. 2005;27: 634-7.

3. Augoustides JGT, Szeto WY, Desai ND, Pochettino A, Cheung AT, Savino JS et al. Classification of acute type a dissection: focus on clinical presentation and extent. Eur J Cardiothorac Surg. 2011;39:519-22.

4. Halstead JC, Meier M, Etz C, Spielvogel D, Bodian CA, Wurm M, et al. The fate of the distal aorta after repair of acute type A aortic dissection. J Thorac Cardiovasc Surg. 2007; 133:127-35

5. Frederick JR, Yang E, Trubelja A, Desai ND, Szeto WY, Pochettino A, et al Ascending aortic cannulation in acute type a dissection repair. Ann Thorac Surg. 2013;95:1808-11

6. Geirsson A, Bavaria JE, Swarr D, Keane MG, Woo YJ, Szeto WY, Pochettino A Fate of the residual distal and proximal aorta after acute type a dissection repair using a contemporary surgical reconstruction algorithm. Ann Thorac Surg. 2007;84:1955-64 